\title{
Polymeric Microcapsules Production from Sodium Alginic Acid for Cell Therapy
}

\author{
Ana Carolina Vale Campos Lisboa a, Maria das Graças da Silva Valenzuela ${ }^{\mathrm{a}}$, Gisella Grazioli, \\ Francisco Rolando Valenzuela Díaz, Mari Cleide Sogayar ${ }^{\mathrm{a}}$ \\ aInstitute of Chemistry, University of São Paulo, Av. Prof. Lineu Prestes, 748, \\ Bloco 9, superior, 05508-900 São Paulo - SP, Brazil \\ ${ }^{\mathrm{b}}$ Politecnic School, University of São Paulo, Av. Prof. Luciano Gualberto, 380, \\ Travessa 3, 05508-900 Butantã, São Paulo - SP, Brazil
}

Received: February 13, 2007; Revised: December 3, 2007

\begin{abstract}
Development of polymeric materials has been increasingly emphasized in Biomedicine. Here, we evaluate the use of microcapsules made of Biodritin ${ }^{\circledR}$, a biocompatible polymer compound which contains sodium alginic acid, a natural polymer extracted from algae, and Cis-Chondroitin sulfate, a glycosaminoglycan from the extracellular matrix. Gelation of this polymer into microcapsules is achieved by dropping the compound into $\mathrm{BaCl}_{2}$ or $\mathrm{CaCl}_{2}$ gelling solutions. A functional microcapsule is dependent on its permeability, mechanical stability, immunoisolation capacity and biocompatibility. The mechanical stability of Biodritin-barium and Biodritin-calcium microcapsules was investigated after rotational stress upon in vitro culture and in vivo implantation. Viability studies of encapsulated cells were also performed to assess other functional parameters of the microcapsules. When subject to rotational stress, Biodritin-barium microcapsules exhibited breaks, whereas the Biodritincalcium microcapsules did not. Both kinds of Biodritin ${ }^{\circledR}$ microcapsules proved to be mechanically resistant in in vitro and in vivo studies. However, the Biodritin-calcium material was found to be more elastic while the Biodritin-barium microcapsules displayed a more plastic behavior. These properties seem to be determinant for viability of the encapsulated cell's, since the Biodritin-calcium microcapsules presented more viable cells than the Biodritin-barium microcapsules.
\end{abstract}

Keywords: biomaterials, alginate, microcapsules, cell therapy

\section{Introduction}

Since 1964, the idea of coating cells with ultra fine membranes of polymeric nature, on microcapsule, has been pursued ${ }^{1}$. Microcapsulation of cells represents an alternative to cell transplant, abrogating the requirement for immunosuppressive drugs to avoid graft rejection. In the case of diabetes, the methodological principle consists of coating purified pancreatic islets with a semi-permeable capsule, preserving their morphological and functional integrity ${ }^{2}$. This capsule must be a physical barrier that prevents the entrance of lymphocytes and other cells of the immune system into the capsule, however, it must be permeable to low molecular weight substances, such as nutrients, electrolytes, oxygen and glucose $\mathrm{e}^{3-5}$. Therefore, encapsulation allows the use of cells of other animals, and also the use of stem cells, aiming to overcome the limited access to organs of cadaveric donors.

This technology has been proved to be success in experimental clinical studies, in patients maintained in the absence of immunosuppressive therapy, for treatment of type 1 diabetes mellitus and hypoparathyreoidism ${ }^{6-8}$.

The material used to generate the microcapsules is expected to be biocompatible and to display mechanical and chemical stability and permeability to low molecular weight nutrients. Several materials are being tested for use in the microencapsulation of cells, but alginate is the most widely studied polymer ${ }^{2,9}$. In addition to being compatible, alginate has the property of passing from the fluid to the gel state under physiological conditions, being the material of choice relative to the others which require drastic conditions for gelation ${ }^{10}$.
Alginate is obtained from the Phaeophyceae brown seaweeds, as linear non-branched polymers containing of 1,4- $\beta$-D-mannuronic acid (M) and 1,4- $\alpha$-L-guluronic acid (G) residues. These monomers are connected in blocks of M homopolymers (M-M-M), G homopolymers (G-G-G) and MG heteropolymers, which can be alternated (M-G-M-G) or not. Alginate has the property of forming gels in the presence of bivalent ions, the stability of the interaction obeying the following order: $\mathrm{Mg}^{2+}<<\mathrm{Ca}^{2+}<\mathrm{Sr}^{2+}<\mathrm{Ba}^{2+}$. Microcapsules generated with this material display the adequate diffusion and permeability levels ${ }^{11,12}$. These physico-chemical properties of the alginate are directly related to the $\mathrm{G} / \mathrm{M}$ content, varying according to its source. The proportion and distribution of these two monomers determine the physico-chemical properties which are important during application, such as: viscosity, pore size and biocompatibility ${ }^{13}$.

The biocompatibility for microcapsules application was defined as the ability of a biomaterial performs with an appropriate host response been necessary to evaluate the interaction between the biomaterial and the tissues of the exterior, host environment and also between the biomaterial and the encapsulated donor tissue ${ }^{14}$. Microcapsules have been the most intensively studied device because of the spherical shape and small size that offers an optimal surface to volume ratio and an optimal diffusion capacity when compared to large devices ${ }^{14,15}$. The prevention of cellular overgrowth of microcapsules is considered to be a crucial factor in biocompatibility of microcapsules. The growth of host cells on the capsule surface reduces the diffusion of oxygen and nutrients to the encapsulated graft resulting 
in necrosis of enveloped cells ${ }^{15}$. The cellular overgrowth depend the purity of the material alginate and the integrity of the microcapsules. One microcapsule with impurity will activate the immune response of the receptor, and in the same manner, one microcapsule with low mechanical resistance can have the presence of ruptures causing the exposition of the graft to antigens and, consequently, to permit the entrance of mediators of the immune response ${ }^{14-16}$.

The inflammatory reaction is a normal response to the implantation of any device, such as the microcapsules ${ }^{17}$. In any case, it is important that this reaction does not interfere with the function of microencapsulated cells. This reaction frequently starts with the adsorption of proteins to the biomaterial polymer surface, with fibrinogen being the most important protein in this process ${ }^{17}$. Foreign body reaction and, consequently, excessive cellular growth over the capsule need be avoiding because of two important reasons. Firstly for causing a physical and metabolic barrier as has been previously exposed, and, secondly, because the cells may be exposed to cytokines released by macrophages, also causes the death of these cells ${ }^{15}$.

In the present work, we have utilized the Biodritin ${ }^{\circledR}$ (BDTN, Patent in the US: 540519-2004.1, by Marcos Mares-Guia and Camillo Ricorde) to generate microcapsules. Biodritin ${ }^{\circledR}$ is considered to be a new heteropolyssaccharide resulting from conjugation of alginate and chondroitin sulfate, displaying a greater biocompatibility with cells and/or tissues than other biomaterials described to date ${ }^{18}$. It is a chemically controlled polymer, which allows the generation of microcapsules with pores uniform size and a control of the diffusion of immunoglobulin's and, therefore, a greater protection against rejection of the transplanted cells ${ }^{19}$. In our study, we evaluated the mechanical properties of Biodritin-barium and Biodritin-calcium in vitro with rotational stress tests and in vivo with experiments using implantation of these microcapsules in rats. Our results demonstrate that Biodritin ${ }^{\circledR}$ improves the mechanical and functional characterize of alginate microcapsules allowing the choice between Biodritin-calcium and Biodritin-barium microcapsules for use in cell therapy.

\section{Materials and Methods}

\subsection{Materials}

Sodium alginate, Pronova UP LVG ${ }^{\circledR}$, NovaMatrix FMC Biopolymer, Drammen, Norway, chondroitin sulfate, and 3-(4,5-dimethylthiazol-2-yl)-2,5-diphenyl-tetrazolium bromide (MTT), of SIGMA, St. Louis, USA, sodium and barium chloride, dimethyl sulfoxide (DMSO) from Merck, Germany, RINm-5f, from ATCC - The American Type Culture Collection, Manassas, VA.

\subsection{Microcapsules production}

For production of the microcapsules, a solution of Biodritin ${ }^{\circledR}$ at an 80:20 ratio, containing $80 \%$ calcium alginate and $20 \%$ purified chondroitin sulfate, was used. The polymers were diluted in a 0.15 mol. $\mathrm{L}^{-1}$ sodium chloride solution. The polymerization solutions (gelation) tested were $20 \mathrm{mmol} . \mathrm{L}^{-1}$ calcium chloride and $20 \mathrm{mmol} . \mathrm{L}^{-1}$ barium chloride. The microcapsules were obtained by extrusion of the alginate solution in a micro-needle using a flow syringe pump (SP 500 JMS do Brasil, Campinas, SP). An air flow $2.2 \mathrm{~L} / \mathrm{min}$ around the micro-needle is responsible for extracting the drop at the expected speed, allowing generation of microcapsules between 700 and $900 \mu \mathrm{m}$ of diameter. The distance of the needle relative to the surface of the solution is $7.5 \mathrm{~cm}$. After droplet extrusion, the microcapsules remain in gelation solution for more than 5 minutes before being immediately filtered and washed with $\mathrm{NaCl} 0.15$ mol. $\mathrm{L}^{-1}$.

The RINm-5f cells were suspended in a Biodritin ${ }^{\circledR}$ solution in the proportion of $1.5 \times 10^{6}$ cells. $\mathrm{mL}^{-1}$. After incubation in the gelation solution for 5 minutes, the microcapsules were washed twice with a saline solution and, immediately, cultured at $37^{\circ} \mathrm{C}$ in RPMI 1640 medium (LGCBio, Cotia - SP), containing 10\% calf fetal serum (FCS), for in vitro studies, and in serum-free medium, for in vivo studies.

\subsection{In vitro analysis of microcapsules produced in $\mathrm{CaCl}_{2}$ and $\mathrm{BaCl}_{2}$}

For the in vitro test, the microcapsules were incubated at $37^{\circ} \mathrm{C}$ and 5\% $\mathrm{CO}_{2}$ atmosphere, in RPMI 1640 medium, containing $10 \%$ of FCS for 3 weeks. During this period, the microcapsules were evaluated, under the optical microscope, with respect to their shape, swelling and possible ruptures.

\subsection{Mechanical stability test of the microcapsules}

The mechanical stability of empty microcapsules was determined through the rotational stress test. Approximately 180 to 200 microcapsules were transferred to a Petri dish containing a) $20 \mathrm{~mL}$ of a $20 \mathrm{mM} \mathrm{CaCl}_{2}$ solution; and b) $20 \mathrm{~mL}$ of a $20 \mathrm{mM} \mathrm{BaCl}_{2}$. The Petri dish was then subjected to the shearing force caused by agitation at $133 \mathrm{rpm}$, through the rotation in a magnetic agitator with the help of a magnetic needle, at room temperature, for 60 minutes. The damages in the microcapsules were produced both by the fluid movement and by the mechanical contact between the magnetic needle and the microcapsules. The number of damaged microcapsules was observed at every 5 minutes intervals and counted using an optical microscope. The damaged microcapsules were those either lost the spherical shape or had broken parts.

\subsection{In vivo analysis of microcapsules produced in $\mathrm{CaCl}_{2}$ and $\mathrm{BaCl}_{2}$}

Empty microcapsule biocompatibility was investigated with in vivo test. Six male Wistar rat (weighing approximately $300 \mathrm{~g}$ ) supplied from the Biothery of Institute of Chemistry (University of São Paulo, São Paulo, Brazil), were divided in two groups composed of three animals each, in one group it was infused Biodritin-barium microcapsules and in another one it was infused Biodritin-calcium microcapsules. The rats were housed under controlled temperature condition in an air-conditioned room at $20 \pm 2{ }^{\circ} \mathrm{C}$ and under controlled light condition, 12 hours light and 12 hours dark, with food and water provided ad libitum. All procedures were approved by the Internal Care and Use Committee of Institute of Chemistry, University of São Paulo.

For the in vivo test, the empty microcapsules were washed with saline solution and infused in the subcutaneous region of Wistar rat. The animals were anesthetized with a mixture of ketamine (50 mg.mL ${ }^{-1}$; Vetanarcol ${ }^{\circledR}$, König S.A., São Paulo, Brazil) and xylazine hydrochloride $\left(20 \mathrm{mg} \cdot \mathrm{mL}^{-1}-\mathrm{Kensol}^{\circledR}\right.$, König S.A., São Paulo, Brazil), intraperitoneally, after a previous administration of Acepromazine (3 mg.kg ${ }^{-1}$ - Univet S.A., São Paulo, Brazil, i.m.), a pre-anesthetic medication. Through a small $(0.5 \mathrm{~cm})$ incision in the dorsal region, $0.5 \mathrm{~mL}$ of microcapsules suspension in sterile saline solution was infused using a $3 \mathrm{~mL}$ syringe and a $14 \mathrm{G}$ Jelco.

After four weeks, the animals were sacrificed with high dose of anesthetic solution (ketamine and xylazine) and the microcapsules were organized in one granuloma. The membrane of the granuloma was disrupted and the microcapsules were fixed in $10 \%$ buffered formalin for the microcapsules evaluation. The parameters evaluated were: resistance, with lost of spherical shape or with broken parts; swelling, when the microcapsules diameter was greater than before the implant; and cellular overgrowth on their surface, when it was observed under phase contrast microscopy. 


\subsection{Evaluation of citotoxicity microcapsules and metabolic activity of encapsulated cells}

For the evaluation of eventual citotoxicity of the microcapsules and of the metabolic activity of the encapsulated RINm-5f cells, four different compositions were tested, Biodritin-barium, Biodritin-calcium, Alginate-barium and Alginate-calcium. The test was through the colorimetric MTT assay, according to Haque, $2004^{20}$. The MTT assay is based on the ability of the mitochondrial dehydrogenase enzyme, present in viable cells, to convert MTT to an insoluble form, namely: formazan crystals. The amount of crystals formed can be quantified in the spectrophotometer. Approximately 30 microcapsules, containing 2 to $3 \times 10^{4}$ cells each capsule, were incubated with $100 \mu \mathrm{L}$ of RPMI medium in a 96 wells plate and $25 \mu \mathrm{L}$ of a MTT solution (1\% in PSB) were applied in each well for 24 hours before the defined culture days. It is important to do this time of MTT incubation for permit all diffusion of the reagent inside of the microcapsules. After this time the culture medium containing MTT was removed and the microcapsules were washed once with PBSA (without calcium or magnesium). The crystals formed were solubilized by adding $200 \mu \mathrm{L}$ of DMSO. After 30 minutes of DMSO incubation, the absorption, at $570 \mathrm{~nm}$, was measured using the spectrophotometer for 96 wells plates. The number of cells was obtained using a calibration curve that correlates the number of cells with absorbance at $570 \mathrm{~nm}^{20}$. The encapsulated cells were keeping in culture for total 15 days and the analyses were performed at 2, 4, 7, 10 and 15 days of culture. For the statistical analyses one-way ANOVA with Tukey post test was performed using GraphPad Prism version 4.00 for Windows (GraphPad Software, San Diego California USA).

\section{Results and Discussions}

This work presents the study of a new compound of alginate with chondroitin sulfate for do calcium and barium-microcapsules. Most of the works with alginate-based microcapsules are using calcium solution for the gelation and the beads are coating with a polycation such as poly-L-lysine (PLL) to produce one immnuneprotective membrane. The polycations are cover, in sequence, with another layer of $\mathrm{Ca}$-alginate. The presence of the polycation increases the mechanical stability and decrease the porosity of the membrane in comparison to only alginate microcapsules ${ }^{14}$. However, some physico-chemical analysis of these microcapsules showed one inadequate binding between the PLL and the outer Ca-alginate layer used to protect the Lysine positive charge which induce cytokine production in monocytes and cause the cellular necrosis ${ }^{21-24}$. These findings have serious implications for biocompatibility issues associated with microcapsules since it implies that the proinflamatory polycations such as PLL is always on the surface of the microcapsules, in direct contact with the hostinflamatory cells in the vicinity. In another side, there are works with alginate-based microcapsules using barium solution for the gelation and no-coating beads. Barium-alginate microcapsules were presented more stable than calcium-alginate and with optimal biocompatibility when implanted in animals ${ }^{25,26}$. However, the molecular weight cutoff of barium-alginate microcapsules is bigger than immunoglobin molecular weight being permeable to it ${ }^{27}$. One implication for this application is that barium-alginate microcapsules can't be used in xenotransplantation (transplant between different species) ${ }^{27}$. The Biodiritn ${ }^{\circledR}$ can be one alternative solution for the use of immunogenic polycations when calcium gelation is the single option.

\subsection{In vitro evaluation of microcapsules produced in $\mathrm{CaCl}_{2}$ and $\mathrm{BaCl}_{2}$ gelation solutions}

Microcapsules produced in calcium chloride or barium chloride gelation solutions, maintained in culture medium, at $37^{\circ} \mathrm{C}$, for three weeks, displayed good mechanical stability since the microcapsules' diameter did not change significantly (Figure 1). However, microcapsules produced in calcium chloride solution showed a lower refringence when observed under phase contrast microscopy and, also, greater swelling, with an increase in diameter of approximately $150 \mu \mathrm{m}$. On the other hand, microcapsules produced in barium chloride solution showed greater refringence, with clear cut edges when observed under phase contrast microscopy, and one lower swelling, with a maximum increase in diameter of $100 \mu \mathrm{m}$.

\subsection{Mechanical stability of the microcapsules}

The mechanical resistance of the microcapsules generated was assessed through rotational stress measurements. Only the microcapsules made using $\mathrm{BaCl}_{2}$ as a gelation solution were damaged by the impact.

The results are shown in Figure 2. After one hour, the microcapsules produced with $\mathrm{BaCl}_{2}$ were completely damaged, while those produced with $\mathrm{CaCl}_{2}$ remained intact (Figure 3a). It is possible to observe two periods between 25-30 and 35-40 minutes, where no substantial increase in damaged microcapsules occurs. During this period, the existence of the debris was observed among the microcapsules produced with $\mathrm{BaCl}_{2}$. This debris probably originated from

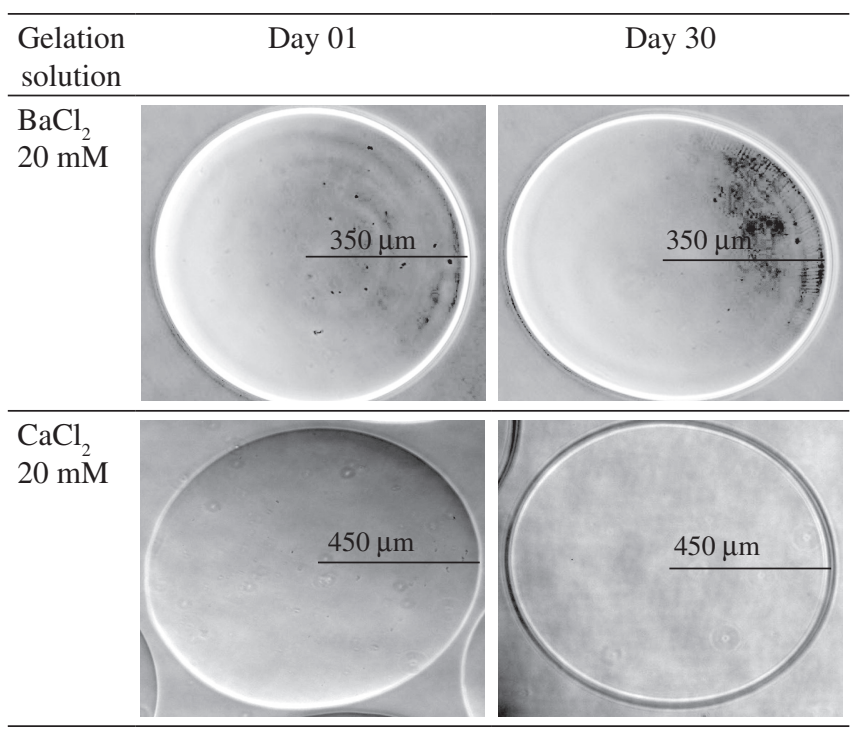

Figure 1. Comparative evaluation under phase contrast microscopy of empty microcapsules produced with Biodritin ${ }^{\circledR}$ in different gelation solutions $(20 \mathrm{mM}$ $\mathrm{CaCl}_{2}$ or $20 \mathrm{mM} \mathrm{BaCl}_{2}$ ) after thirty days in culture.

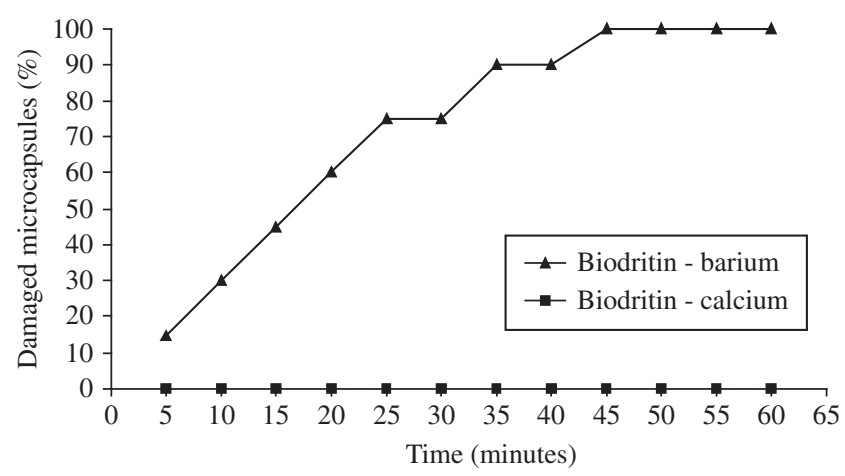

Figure 2. Variation in the number of damaged microcapsules after being subjected to rotational stress. The microcapsules were counted in each five minutes during the experiments using optical microscope. 


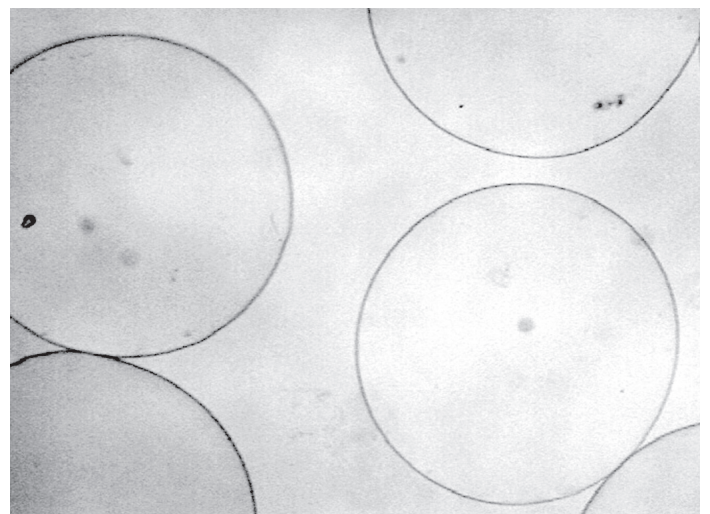

(a)

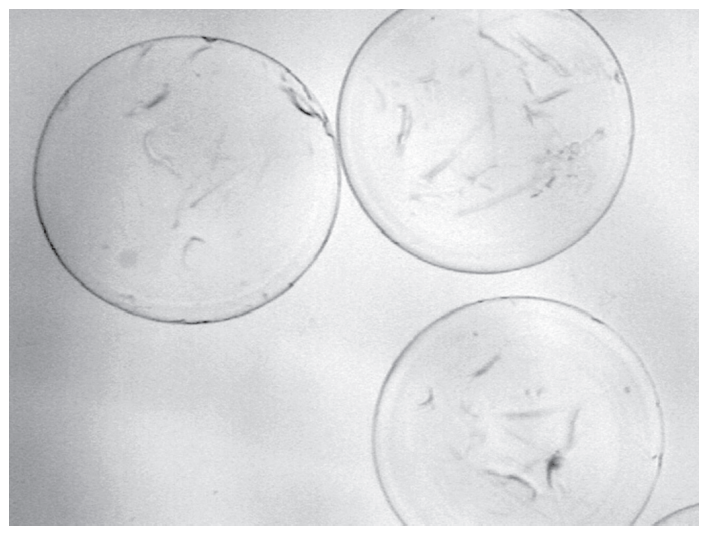

(b)

Figure 3. Biodritin ${ }^{\circledR}$ microcapsules after being subjected to shearing generated by rotation at $133 \mathrm{rpm}$. a) after 60 minutes of rotation the Biodritin-calcium microcapsules resisted to the impact; and b) After 60 minutes of rotation of the Biodritin-barium it was possible to observe debris among the microcapsules and damaged microcapsules.

disintegrated microcapsules and damaged microcapsules (Figure 3b). These results indicate that different ions affect the mechanical resistance of the microcapsules. The microcapsules produced with $\mathrm{BaCl}_{2}$ are less flexible than the microcapsules produced with $\mathrm{CaCl}_{2}$.

\subsection{In vivo evaluation of microcapsules produced in $\mathrm{CaCl}_{2}$ or $\mathrm{BaCl}_{2}$ gelation solutions}

The effect of subcutaneous implantation on microcapsules structure was evaluated in experiments performed in vivo with BDTN microcapsules generated using barium or calcium chloride solutions. The microcapsules were maintained in vivo, in the subcutaneous region of rat for four weeks. The Figure 4 shows the high mechanical stability and biocompatibility of these microcapsules after the implant. Disrupted microcapsules, splits in their membrane or peri-capsular growth were not observed. Indications of biodegradation upon the explants of the microcapsules were not found either. Both types of microcapsules were organized in one granuloma, being compressed inside of this structure. A notable difference between the two types of microcapsules is that barium-capsules, after be explanted, remain flat, with the distortions caused by the compactation inside the granuloma. And calcium-capsules showed an elastic behavior, they not remain deformed after the tissue pressure in the granuloma.

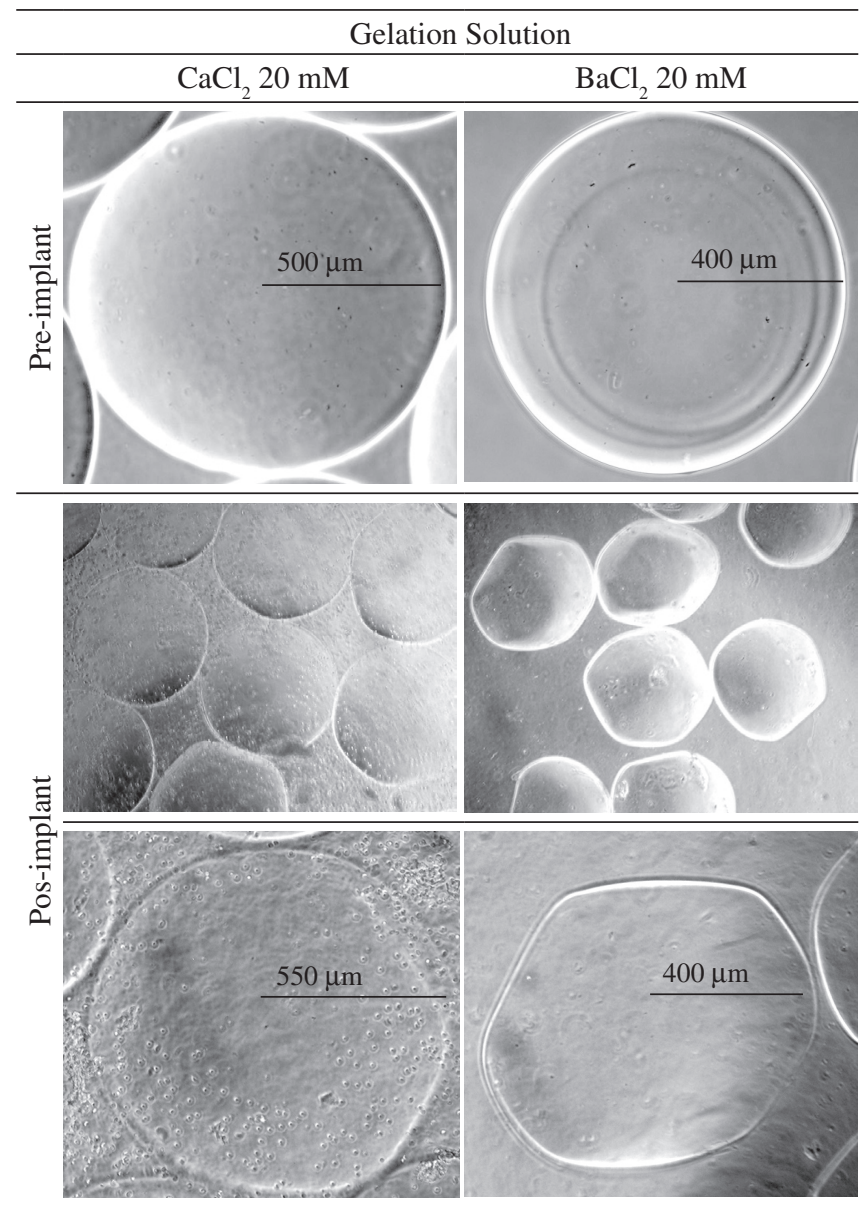

Figure 4. Comparative evaluation, under phase contrast microscopy, of empty microcapsules produced with Biodritin ${ }^{\circledR}$ in $20 \mathrm{mM} \mathrm{CaCl}_{2}$ or $20 \mathrm{mM} \mathrm{BaCl}_{2}$. Pre-implant observation and after four weeks of subcutaneous implant in Wistar rats.

\subsection{Evaluation of the citotoxicity of the microcapsules and of the metabolic activity encapsulated cells.}

The citotoxicity of the microcapsules and the metabolic performance of encapsulated cells for microcapsules generated in barium or calcium chloride gelation solutions were compared. It was possible to evaluate the influence of the ions (calcium and barium) in the biocompatibility of the microcapsules as well as the influence of chondroitin sulfate combined with alginate (Biodritin ${ }^{\circledR}$ versus alginate). Figure 5 represents the number of cells per $30( \pm 3)$ microcapsules at several time intervals. All microcapsules revealed an increase in the number of cells and, consequently in metabolic activity. Nevertheless, the calcium gellified microcapsules show a higher increase compared to barium gellified microcapsules with statistical significance of $p<0.05$ for alginate microcapsules and $\mathrm{p}<0.01$ for Biodritin ${ }^{\circledR}$ microcapsules. This is probably a consequence of the higher flexibility and lower density of the calcium microcapsules, allowing proliferation of the cells in their interior. Up to the seventh day, microcapsules made of Biodritin $^{\circledR}$ showed a major growth of the cells when compared to their corresponding microcapsules generated with alginate only, but with out siginificance statistical (Figure 6). After this period, their performance is very similar, namely: $\mathrm{BDTN}-\mathrm{Ba}^{2+}$ compared with $\mathrm{ALG}^{-\mathrm{Ba}^{2+}}$ and BDTN-Ca ${ }^{2+}$ with ALG-Ca ${ }^{2+}$. 


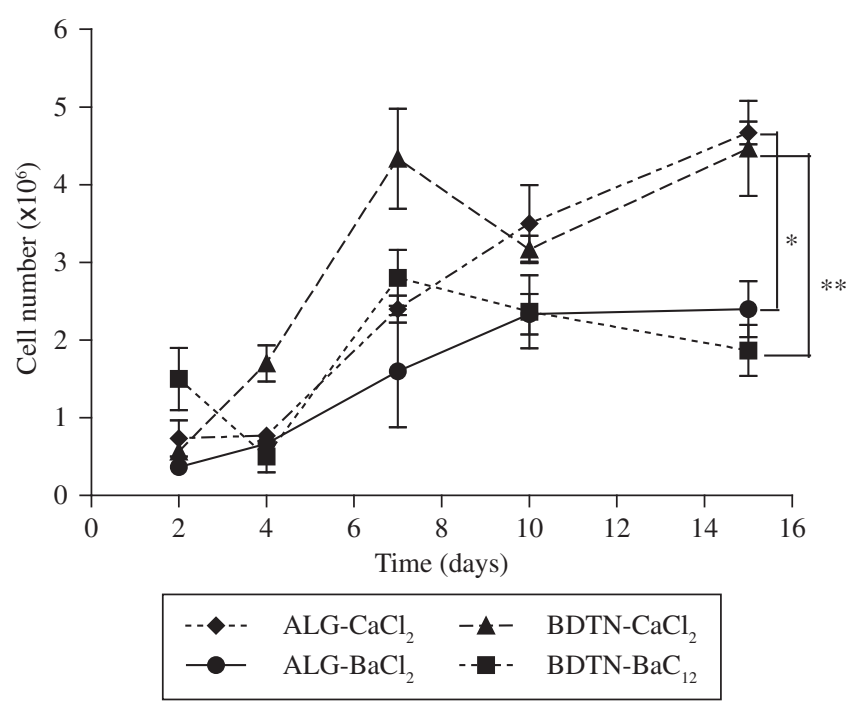

Figure 5. Kinetics of metabolic activity of RINm-5 $f$ cells encapsulated in $\mathrm{BDTN}+\mathrm{BaCl}_{2}$ (square), $\mathrm{BDTN}+\mathrm{CaCl}_{2}$ (circle), $\mathrm{ALG}+\mathrm{BaCl}_{2}$ (lozange) and $\mathrm{ALG}+\mathrm{CaCl}_{2}$ (triangle), ${ }^{*} \mathrm{p}<0.05$ and ${ }^{*} \mathrm{p}<0.01$ (One-way ANOVA with Tukey post test). BDTN - Biodritin ${ }^{\circledR}$, ALG - Alginate.

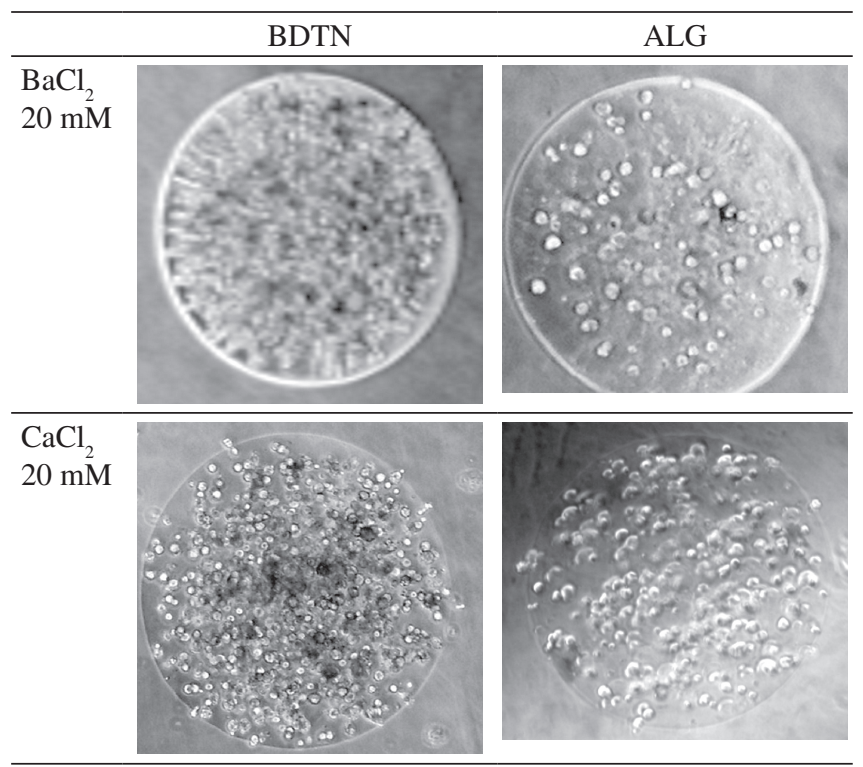

Figure 6. Photomicrography of RINm-5f cells encapsulated in BDTN$\mathrm{BaCl}_{2}, \mathrm{BDTN}-\mathrm{CaCl}_{2}, \mathrm{ALG}-\mathrm{BaCl}_{2}$ and ALG-CaCl${ }_{2}$ after 7 days of cultivation, culturing as described in Material and Methods. BDTN - Biodritin ${ }^{\circledast}$, ALG - Alginate.

\section{Conclusion}

The results of this study show that the Biodritin-calcium biomaterials are more adequate for cell transplantation than the Biodritinbarium. However, better understanding of microcapsules properties with respect to the different ions responsible for their gelation is necessary. More detailed experiments on the functionality of the microcapsules, in vivo, need to be performed.

\section{Acknowledgments}

This work was supported by Fundação de Amparo a Pesquisa do Estado de São Paulo - FAPESP, Conselho Nacional de Desenvolvi- mento Científico e Tecnológico - CNPq and Financiadora de Estudos e Projetos - FINEP.

\section{References}

1. Chang TM. Semipermeable Microcapsules. Science. 1964; 146(3643):524-525.

2. Calafiore R, Basta G. In: Ricordi C, editor. Microencapsulation of pancreatic islets: Theoretical principles, technologies and practice. revised ed. New York: R.G. Landes; 1995. p. 587-609.

3. Calafiore R. Perspectives in pancreatic and islet cell transplantation for the therapy of IDDM. Diabetes-Care. 1997; 20(5):889-96.

4. Lanza RP, Beyer AM, Staruk JE, Chick WL. Biohybrid artificial pancreas. Long-term function of discordant islet xenografts in streptozotocin diabetic rats. Transplantation. 1993; 56(5):1067-1072.

5. Lanza RP, Butler DH, Borland KM, Taruk JE, Faustman DL, Solomon BA et al. Xenotransplantation of canine, bovine, and porcine islets in diabetic rats without immunosuppression. Proceedings of the National Academy of Sciences. 1991; 88(24):11100-11104.

6. Calafiore R, Basta G, Luca G, Lemmi A, Racanicchi L, Mancuso F, et al. Standard technical procedures for microencapsulation of human islets for graft into nonimmunosuppressed patients with type 1 diabetes mellitus. Transplantation Proceedings. 2006; 38(4):1156-1157.

7. London NJM, Robertson GSM, Chadwick DR, Johnson PRV, James RFL, Bell PRF. Human islet isolation and transplantation. Clinical Transplantation. 1994; 8(5):421-459.

8. Secchi A, Di Carlo V, Pozza G. Pancreas and islet transplantation current progresses, problems and perspectives. Hormone and Metabolic Research. 1997; 29(1):1-8.

9. Sun Y, Ma X, Zhou D, Vacek I, Sun AM. Normalization of diabetes in spontaneously diabetic cynomologus monkeys by xenografts of microencapsulated porcine islets without immunossuppression. The Journal of Clinical Investigation. 1996; 98(6):1417-1422.

10. Orive G, Hernandez RM, Rodriguez Gascon A, Calafiore R, Chang TM, De Vos P, et al. History, challenges and perspectives of cell microencapsulation. Trends Biotechnology. 2004; 22(2):87-92.

11. Rafael E, Wernerson A, Arner P, Wu GS, Tibell AE. In vivo evaluation of glucose permeability of an immunoisolation device intended for islet transplantation: a novel application of the microdialysis technique. Cell Transplantation. 1999; 8(3):317-326.

12. Sharkawy AA, Klitzman B, Truskey GA, Reichert WM. Engineering the tissue which encapsulates subcutaneous implants. I. Diffusion properties. Journal of Biomedical Mateials Research. 1997; 37(3):401-412.

13. Zimmermann H, Zimmermann D, Reuss R, Feilen PJ, Manz B, Katsen A, et al. Towards a medically approved technology for alginate-based microcapsules allowing long-term immunoisolated transplantation. Journal of Materials Science. Materials in Medicine. 2005; 16(6):491-501.

14. de Vos P, Faas MM, Strand B, Calafiore R. Alginate-based microcapsules for immunoisolation of pancreatic islets. Biomaterials. 2006; 27(32):5603-5617.

15. de Groot M, Schuurs TA, van Schilfgaarde R. Causes of limited survival of microencapsulated pancreatic islet grafts. The Journal of Surgical Research. 2004; 121(1):141-150.

16. de Vos P, van Hoogmoed CG, van Zanten J, Netter S, Strubbe JH, Busscher HJ. Long-term biocompatibility, chemistry, and function of microencapsulated pancreatic islets. Biomaterials. 2003; 24(2):305-312.

17. Tang L, Eaton JW. Natural responses to unnatural materials: A molecular mechanism for foreign body reactions. Molecular Medicine. 1999; 5(6):351-8.

18. Mares-Guia M, Ricordi C., Inventors. Biomm Inc. and Diabetes Research Institute, assignee. Novel hetero-polysaccharide conjugates, novel S-INP polysaccharide gels and methods of making and using the same. United States patent 540519-2004.1.and trademark office application for letters patent. 1997 Jun 17. 
19. Orive G, Hernandez RM, Gascon AR, Igartua M, Pedraz JL. Development and optimisation of alginate-PMCG-alginate microcapsules for cell immobilisation. International Journal of Pharmaceutics. 2003; 259(1-2):57-68.

20. Haque T, Chen H, Ouyang W, Martoni C, Lawuyi B, Urbanska AM, et al. Superior cell delivery features of poly(ethylene glycol) incorporated alginate, chitosan, and poly-L-lysine microcapsules. Molecular Pharmaceutics. 2005; 2(1):29-36.

21. Strand BL, Ryan TL, In't Veld P, Kulseng B, Rokstad AM, Skjak-Brek $\mathrm{G}$, et al. Poly-L-Lysine induces fibrosis on alginate microcapsules via the induction of cytokines. Cell Transplantation. 2001; 10(3):263-277.

22. de Vos P, Hoogmoed CG, Busscher HJ. Chemistry and biocompatibility of alginate-PLL capsules for immunoprotection of mammalian cells. Journal of Biomedical Materials Research. 2002; 60(2):252-259.

23. van Hoogmoed CG, Busscher HJ, de Vos P. Fourier transform infrared spectroscopy studies of alginate-PLL capsules with varying com- positions. Journal of Biomedical Materials Research. Part A. 2003; 76(1):172-178.

24. de Vos P, van Hogmoed CG, de Han BJ, Busscher HJ. Tissue responses against immunoisolating alginate-PLL capsules in the immediate posttransplant period. Journal of Biomedical Materials Research. 2002; 62(3):430-437.

25. Klöck G, Pfeffermann A, Ryser C, Gröhn P, Kuttler B, Hahn HJ, et al. Biocompatibility of mannuronic acid-rich alginates. Biomaterials. 1997; 18(10):707-713.

26. Duvivier-Kali VF, Omer A, Parent RJ, O’Neil JJ, Weir GC. Complete protection of islets against allorejection and autoimmunity by a simple barium-alginate membrane. Diabetes. 2001; 50(8):1698-1705.

27. Omer A, Duvivier-Kali V, Fernandes J, Tchipashvili V, Colton CK, Weir GC. Long-term normoglycemia in rats receiving transplants with encapsulated islets. Transplantation. 2005; 79(1):52-58. 